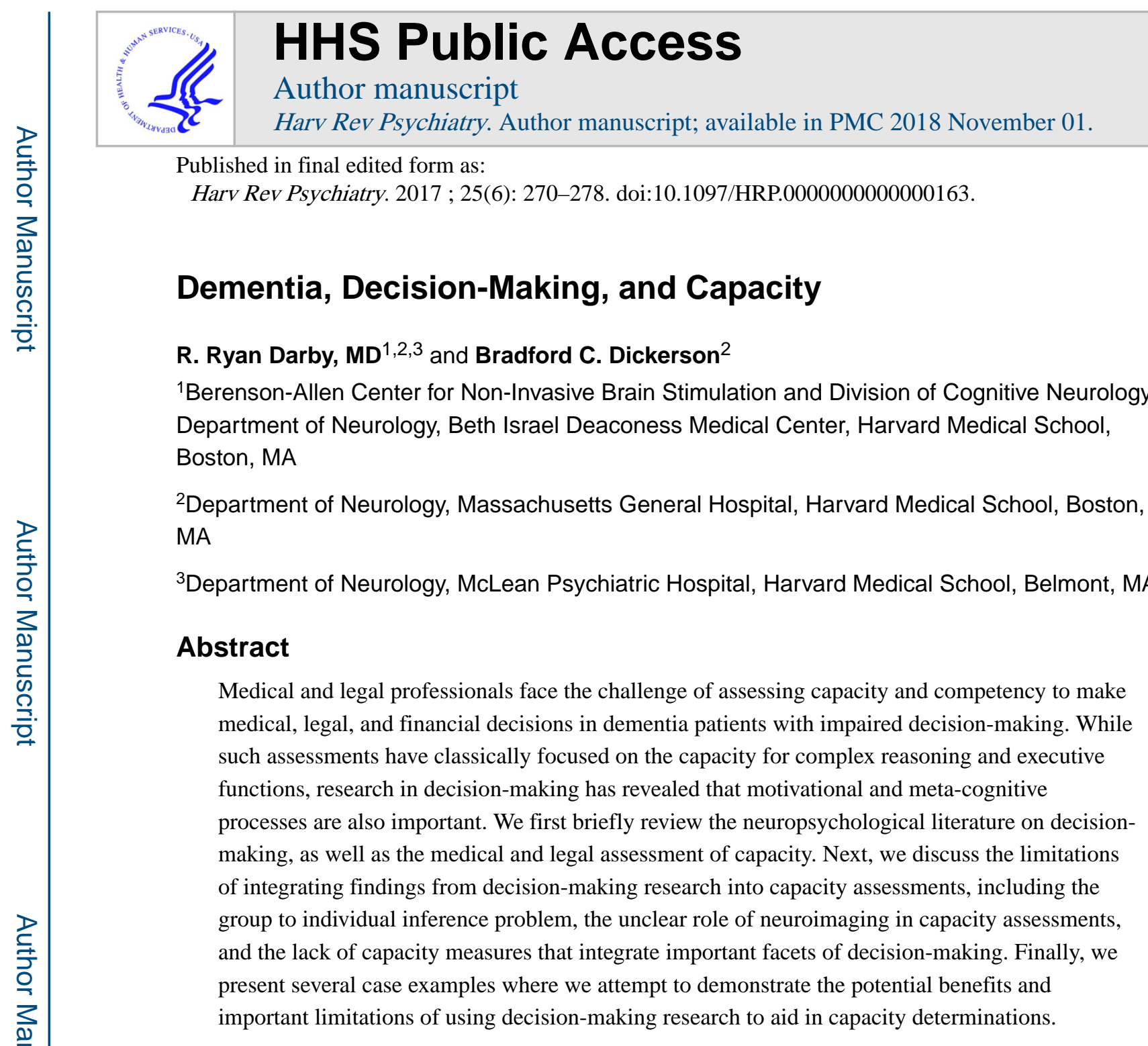

Keywords

Dementia; Law; neuroethics; ethics; decision-making

\title{
Introduction
}

Dementia is a clinical term for brain conditions, including many neurodegenerative diseases, characterized by the progressive loss of mental faculties, ultimately leading to an inability to care for oneself ${ }^{1}$. Alzheimer's disease is the most common form of dementia, although Lewy body dementia, Parkinson's disease dementia, Vascular Dementia, and Frontotemporal Dementia are also encountered ${ }^{1}$. While early in the disease course these different types of dementia can impair specific cognitive processes, such as memory, language, behavior, or executive functions, all types of dementia can impair decision-making ${ }^{2}$. Impaired decisionmaking can have important consequences when considering medical capacity assessments or the legal determination of competency in patients suffering from dementia. As the number of

*Correspondence to: Ryan Darby, rdarby@bidmc.harvard.edu, Berenson-Allen Center for Noninvasive Brain Stimulation, Beth Israel Deaconess Medical Center, 330 Brookline Ave, Kirstein Building KS 158, Boston, MA 02215. 
patients with dementia is expected to rise in the next several decades ${ }^{3}$, an understanding of how decision-making becomes impaired in patients with dementia is necessary.

The study of decision-making in neurological patients has often focused on deficits in reasoning and executive functions. However, research into the neural basis of decisionmaking has demonstrated that many other neuropsychological processes contribute to decision-making in various contexts, including those important for motivation related to reward and punishment ${ }^{4}$, and in monitoring of one's cognitive deficits, a process referred to as meta-cognition ${ }^{5,6}$. Lawyers, judges, and even medical practitioners may not consider these less recognized components of decision-making when assessing capacity in patients with dementia.

In this article, we review the neuropsychological processes contributing to decision-making, and how these processes are impaired in patients with dementia. Next, we describe the medical concept of capacity and legal definition of competency, which both involve a binary determination of a patient's ability to make specific types of decisions. We will discuss the current limitations in applying research in decision-making towards these determinations, including the group to individual inference problem, the uncertain role of neuroimaging, and the need to develop additional tools integrating decision-making tasks with capacity assessments. Finally, we use case studies to examine how clinicians' assessments of impaired decision-making might influence determinations of capacity and competency.

\section{Neuropsychology of Decision-Making}

\section{Executive Functions}

Decision-making is the process of selecting an appropriate action from a number of possible actions ${ }^{2,7-9}$. Determining the appropriate course of action involves a number of different cognitive processes, including selecting one's goal, motivation to achieve this goal, weighing the likely consequences of different options, and determining which expected consequences would best fit with these goals ${ }^{7}$. This is not a static process: goals may shift at various points, as may the likelihood of different outcomes for selected actions. Finally, multiple goals may be present simultaneously, so that one must choose actions that fulfill some goals while at the same time inhibiting decisions that maximize other competing goals ${ }^{7,9}$. These abilities have been collectively referred to as executive functions ${ }^{10}$. Many models of executive functions have been proposed, including those focusing on selective attention ${ }^{11}$, working memory ${ }^{12}$, on top-down modulation or control ${ }^{7,9}$, on selection and execution of goal directed behavior ${ }^{7}$, and on context-specific action response memories, or structure event complexes ${ }^{13}$.

In each theory, the broader model of executive function can be further divided into specific processes that have been studied extensively. Proposed executive function processes have included, for example, initiation, volition, and energization; working memory, selective attention, set-shifting, task-setting, and task maintenance; and response inhibition, monitoring, salience detection, and conflict control ${ }^{8}$. Energization involves the initiation and maintenance of goal-directed behavior ${ }^{8}$. Loss of initiation can result in clinical syndromes of apathy, abulia, and akinetic mutism. These syndromes cause a loss in goal-

Harv Rev Psychiatry. Author manuscript; available in PMC 2018 November 01. 
directed behavior, resulting in a failure to make decisions important to daily functioning. Maintenance is the ability to sustain goal-directed behavior over time ${ }^{8}$. This includes the concept of selective attention and vigilance ${ }^{11}$, as well as control over conflicting, more automatic or default responses ${ }^{14}$. Task selection involves selecting the appropriate response to a stimulus given the individual's goals ${ }^{8}$. This involves learning the appropriate response to a stimulus, shifting one's response when the task goal changes (set-shifting), and inhibiting responses that are no longer appropriate (response inhibition). These processes are closely related to the concept of working memory, which involves the retrieval, holding, and manipulation of information necessary to aide in decision-making ${ }^{12}$. Finally, monitoring refers to the process of checking for errors in task performance ${ }^{8}$. This also involves reorienting attention to unexpected stimuli ${ }^{15,16}$. Patients with impaired monitoring do not modify their behavior in response to inappropriate outcomes and may lose the ability to check internal expectations with external reality. A specific type of monitoring of one's cognitive deficits, referred to as meta-cognition, will be discussed in a subsequent section.

Different types of executive functions may involve distinct brain networks. For instance, the frontoparietal or executive control network (Figure 1A) has been associated with executive functions and cognitive control ${ }^{17}$, the dorsal attention network (Figure 1B) with top-down modulation of attention ${ }^{18}$ and the ventral attention network (Figure 1C) with reorienting of attention and monitoring of performance ${ }^{18}$.

\section{Reward, Punishment, and Value}

The cognitive neuroscience of decision-making has also revealed a complex network of brain networks involved in determining the expected reward or punishment associated with different choices 19,20 . While initially described in decisions involving nonsocial, monetary rewards or punishments, more recent research suggests that computations involving social rewards and punishments involve a similar network of regions ${ }^{4}$. This process is sometimes referred to as "model-free" learning, in the sense that it occurs automatically without explicit, conscious predictions of reward or punishment values ${ }^{21}$. The expected value for a given choice is thought to be associated with activity in the ventral tegmental area, nucleus accumbens (Figure 1D), and other portions of the ventral striatum ${ }^{4}$. This value is continuously updated by incorporating reward-prediction errors, or the amount that the actual rewarding experience differed from what was expected with the choice. Finally, regions in the ventral medial prefrontal cortex (vmPFC) are thought to integrate the expected values of many different possible choices in order to form a determination of the decision with the greatest expected reward value ${ }^{4,22}$. This determination gives motivation weights for particular choices, ultimately influencing decision-making ${ }^{19}$. This is particularly relevant to decisions involving choosing between safe and risky options, or in decisions where expected outcomes are ambiguous or uncertain ${ }^{2}$. Value-based decision-making involving punishment is conceptually similar, but is subserved by a distinct neuroanatomical network including the anterior insula, anterior cingulate, and lateral striatum ${ }^{4}$. Several psychological tasks are designed to assess value-based decision-making. Risk aversion asks subjects to choose between a guaranteed amount of money and a gamble to receive a potentially much larger sum of money. Temporal discounting tasks ask subjects to choose between a small sum of money now, or a larger amount of money at a later time. Finally, the Iowa Gambling Task ${ }^{23}$

Harv Rev Psychiatry. Author manuscript; available in PMC 2018 November 01. 
tests ambiguous decision-making, where subjects learn to choose from decks of cards that result in a net increase in money over time, as opposed to decks with higher potential immediate rewards but high potential losses, leading to a net loss of money over time.

\section{Meta-cognition and awareness of deficits}

Self-awareness of cognitive, emotional, and motivational limitations allows a patient to appropriately determine situations where decision-making is likely to be impaired. This awareness of one's cognitive limitations is sometimes referred to as meta-cognition, and loss of this awareness in neurological patients is often called anosagnosia ${ }^{5}$. Metacognition is an important practical skill that allows a patient to adapt their behavior so that events where impaired decision-making are likely occur less often. Metacognition can be assessed by comparing self-ratings vs. caregiver ratings of cognitive abilities, or by comparing selfratings vs. actual performance on cognitive testing ${ }^{6}$. Various tasks have been developed to measure components of meta-cognition, including ease of knowing, feeling of knowing, judgment of knowing, and retrospective confidence ratings ${ }^{5}$. Patients with most types of dementia, including Alzheimer's disease and Frontotemporal Dementia, have been shown to have impaired meta-cognition ${ }^{6}$. Impaired meta-cognition correlates with structural and functional brain abnormalities in parts of the frontal lobe important for monitoring task performance ${ }^{24}$ and may particularly involve right frontal and right anterior insular regions ${ }^{25}$. Finally, loss of meta-cognition may relate to disrupted functional connectivity between these regions and regions involved in memory or other cognitive abilities ${ }^{26}$.

\section{Medical and legal consequences of impaired decision-making}

In the previous section, we discussed the various neuropsychological processes contributing to normal decision-making and impaired decision-making in dementia. In the next section, we will apply this knowledge to better understand the enormous impact impaired decisionmaking can have on dementia patients, families, and society. This includes, for example, physical injuries may occur from impaired driving, use of dangerous tools, or weapons; poor financial decision-making leading to significant loss of wealth; and the risk of elder abuse and exploitation. Because of these concerns, measures are often taken to limit autonomy in patients with impaired decision-making. Such interventions are not taken lightly, and it is therefore important to ensure that these determinations are made as accurately as possible. In the following sections on capacity, competency, and surrogate decision-making, we will discuss how determinations of impaired decision-making are made, highlighting instances where decision-making research could help to inform these processes.

\section{Capacity and Competency}

Capacity refers to the functional determination of whether an individual patient has the ability to adequately make a specific decision, such as financial decisions, or perform a specific task, such as driving ${ }^{27}$. In contrast, competency is the legal determination of whether an impaired mental capacity limits a patient's ability to make a legally relevant decision or action. Physician's play an important role in this process: in most cases, capacity determinations are made in the clinic without adjudication, and even in cases that progress to legal hearings to determine competency, evidence from clinicians is often key. ${ }^{28}$ Importantly, 
capacity is context and decision-specific: a patient may retain the capacity for certain decisions, even if the capacity for other types of decisions is lost. Research has largely focused on the capacity for informed consent ${ }^{29}$. In order to obtain informed consent, a patient must demonstrate four capacities: to understand the information presented, to appreciate how this information relates to their personal situation, to rationally use this information to arrive at a decision, and to maintain a consistent choice over time ${ }^{29}$. Assessments tools for determining capacity for informed consent have been developed, utilizing structured interviews ${ }^{30}$ or by examining a patient's ability to reason through hypothetical medical decision-making vignettes ${ }^{31-34}$. For example, a patient will be given a scenario involving different treatment options, and must use this information to choose a specific treatment. Their response is rated according to their ability to articulate the expected benefit and side effects, to describe how these will affect them personally, use this information to make a treatment choice, and to maintain a consistent choice over time..$^{31-34}$ Impaired capacity for informed consent has also been shown to correlate with verbal fluency ${ }^{35}$, conceptual and confrontational naming ${ }^{36}$, and with general cognitive screens using the mini-mental status exam ${ }^{30,37}$. Finally, impaired meta-cognition has been associated with loss of capacity to consent ${ }^{38}$. Decline in capacity may occur in both $\mathrm{AD}^{39}$ and $\mathrm{MCI}{ }^{40}$, making frequent reassessment of capacity necessary.

The capacity for financial decision making can be defined as "the capacity to manage money and financial assets in ways which meet a person's needs and which are consistent with his/her values and self-interest" ${ }^{41}$. The process can be assessed using structured tools targeting both procedural and decision-making aspects of financial management ${ }^{42}$. Capacity for financial decision making is associated with written arithmetic and executive function task performance 43,44 . Additionally, left angular gyrus atrophy has been associated with diminished financial capacity ${ }^{44}$. Neuropsychological risk factors for financial exploitation or financial abuse in persons with dementia has not been specifically addressed, although this may include abnormal trust in strangers ${ }^{45}$ in addition to executive dysfunction. The clinician's role in financial capacity includes education to patients and families about financial planning, recognizing and screening for impaired financial capacity, recommending interventions to maintain financial independence, and making appropriate referrals when financial capacity is questioned ${ }^{46}$. Determining capacity in other contexts, such as voting ${ }^{47,48}$ and gun ownership ${ }^{49,50}$, has been less standardized, but follows the same logic as assessment of capacity for informed consent and financial capacity.

\section{Surrogate decision-making}

Identification of surrogate decision-makers should be made early in patients at risk of developing impaired capacity. A healthcare proxy is a medical form used to appoint a surrogate decision-maker for healthcare related decisions, whereas a durable power of attorney can also assist in other types of legal and financial decisions as well ${ }^{51}$. In the event that a patient lacks the capacity to complete a healthcare proxy form or select a durable power of attorney, a lengthy legal process of appointing a guardianship and/or conservatorship may be necessary. In other situations, the patient's nuclear family serves as a surrogate decision-maker given their unique knowledge of the patient's preferences, and the common-law precedent of appointing family members as surrogate decision-makers. ${ }^{51}$

Harv Rev Psychiatry. Author manuscript; available in PMC 2018 November 01. 
Surrogate decision-makers should be counseled to make decisions that are consistent with a patient's expressed wishes, values, or preferences, and that are in the best interest of the patient. ${ }^{51}$

\section{Limitations}

In the previous sections, we have outlined the neuropsychological processes contributing to decision-making, as well as the situations where impaired decision-making can effect medical and/or legal determinations of capacity and competency. However, advances in the cognitive neuroscience of decision-making have not significantly affected such determinations. In the following section, we will discuss three reasons for this: (1) difficulty in determining how data regarding decision-making at a population level affects judgments regarding an individual patient's decision-making capacity; (2) that neuroimaging data may not aid capacity determinations beyond behavioral data; and (3) the lack of integration of social cognition, value and reward, and meta-cognition measures into formal capacity assessment tools.

\section{Group to individual inference problem}

Research in decision-making utilizes the scientific method: experiments are conducted to in a large number of subjects and statistically tested to determine commonalities at the group level. In contrast, capacity, whether in the medical or legal setting, involves determining whether an individual patient has impaired decision-making specifically related to the question at hand. This discrepancy between scientific knowledge at the group level, and applied science at the individual level, has been called the group to individual (G2i) inference problem. ${ }^{52}$ This problem is very similar to those faced by clinicians every day, where diagnoses, treatments, and outcomes informed by clinical research at the group level must be applied to decisions regarding specific, individual patients. ${ }^{53}$

Given this limitation, how might decision-making science influence determinations of capacity? Faigman and colleagues suggest that such research can be used in two ways: to present general scientific evidence to educate jurors or other fact-finders to help them understand important facets of a case (framework evidence), or to apply general scientific findings to make specific judgments in individual cases (diagnostic evidence) ${ }^{52}$ For example, evidence regarding the validity of eyewitness testimony is used to educate jurors regarding the limitations and biases of such accounts at the group level (framework evidence); however, there is consensus that these researchers should not make judgments about the validity of eyewitness testimony in a specific case. ${ }^{52}$ In contrast, a forensic psychiatrist may very well testify not only that persons with schizophrenia have impaired decision-making, but also that the individual patient in questions has schizophrenia, has impaired decision-making, and even that this impairment renders the patient legally insane. ${ }^{53}$

It is unclear where decision-making evidence should fall along this spectrum. In some cases, the recognition that reward/punishment, emotions, social cognition, and meta-cognition contribute to decision-making could be useful as framework evidence. However, the degree to which these psychological processes can be applied to a specific case depends on the 
scientific validity of the measures in clinical populations, and how well these measures capture components that are relevant to the medical or legal question of capacity at hand. For example, one might be able to demonstrate impairment in reward processing in a clinical patient, but proving that this impairment contributed to a specific illegal action would require additional evidence demonstrating that reward processing is critically involved in that decision.

\section{Utility of neuroimaging evidence}

Capacity and competency are judgments based on mental states. ${ }^{54}$ Behavioral testing can provide valuable information regarding whether there is impairment in neuropsychological processes contributing to the mental states related to decision-making capacity. In many instances, neuroimaging research has identified specific brain regions involved in these neuropsychological processes. ${ }^{55} \mathrm{~A}$ controversial question becomes whether using neuroimaging evidence to show abnormal functional brain activity could therefore add value in determining medical or legal capacity. ${ }^{54,56}$

Stephen Morse, among others, has argued that neuroimaging is unlikely to add value beyond behavioral data in most cases. Showing functional neuroimaging abnormalities in a given patient is irrelevant if this abnormality is not associated with behavioral differences in the patient, and if such behavioral differences exist, it is unclear that the neuroimaging evidence helps in determining capacity or competency. Additionally, neuroimaging findings are currently unable to aid in the clinical diagnosis in psychiatric diseases. However, in the case of persons with dementia, neuroimaging is part of routine clinical care and improves diagnostic accuracy. Current research definitions for Alzheimer's disease ${ }^{57}$ and frontotemporal dementia,${ }^{58}$ for example, define typical behavioral syndromes as possible $\mathrm{AD}$ or FTD, while the presence of neuroimaging abnormalities (amyloid PET scan in AD, frontal or temporal abnormalities on MRI or PET for FTD) are necessary to diagnose probable dementia. As a patient's clinical diagnosis in dementia provides a potential causal explanation for a change in behavior, such evidence can provide additional value in specific cases. However, it is important to note that even with a behavioral profile and neuroimaging consistent with a diagnosis of dementia, assessment of a patient's decision-making related to a specific action is still necessary for medical determinations of capacity and legal determinations of competency. ${ }^{54}$

\section{Lack of integration of decision-making research with formal capacity assessments}

Finally, there is a lack of integration between tasks designed to test certain aspects of decision-making, and tools designed specifically to assess for capacity to make specific types of decisions. ${ }^{27}$ For example, reward and punishment may contribute to financial decision-making, but tasks used to test these constructs in other settings may not translate well to the specific situation of financial decision-making. Additionally, other processes, such as reasoning and planning, also contribute to these decisions, and the interaction between such domains may not be apparent when each domain is tested separately.

More ecologically valid measures designed to test capacity for financial decisions, however, may not assess the effects of reward and punishment on these decisions. There is therefore a 
critical need for decision-making science to inform the design of capacity measures to reflect the multiple neuropsychological processes contributing to these decisions.

Preliminary work on financial decision-making in the elderly is beginning to show how such integration might take place: changes in risk aversion and temporal discounting have been shown to occur with aging and relate to financial decision-making, ${ }^{59}$ and susceptibility to scams is related to abnormal memory and processing speeds. ${ }^{60}$ Using such information to further refine capacity assessment tools is necessary to improve the applicability of behavioral assessments at the group level with abnormalities important for capacity at the individual level.

\section{Case Studies in Dementia, Decision-Making, and the Law}

Impaired executive functions, reward-based valuation, social cognition, emotion, and metacognition can all be present in patients with dementia, leading to deficits in decisionmaking. These deficits can lead to an inability to make legal, financial, and medical decisions effectively, and the potential for financial exploitation and abuse. In the following section, we will present a series of hypothetical cases where issues of capacity and competency arise in patients with dementia and impaired decision-making. In each case, we will discuss how clinical, neuropsychological, and neuroimaging evidence is or is not useful in determining capacity or competency.

\section{Case 1: Parkinson's disease with impulse control disorder}

A 68 year-old man with Parkinson's disease for the past 7 years has recently been started on a dopamine agonist. In the last three months he has begun gambling excessively and soliciting prostitutes, losing nearly $\$ 100,000$ dollars from his savings. He is now estranged from his wife and living with a friend, but is on the verge of losing his housing as he recently started using cocaine. He has now been summoned to court by his debtors.

Impulse control disorders (ICD) are increasingly recognized to occur in patients with Parkinson's disease ${ }^{61}$. These behaviors include pathological gambling, addiction, sexual behaviors, and binge eating. Un-medicated patients with Parkinson's disease do not have an increased incidence of ICD compared to healthy controls ${ }^{62}$. However, up to $25 \%$ of medicated patients will develop ICD once started on medications ${ }^{63}$. ICD are more common in patients being treated with dopamine agonists compared to other medicines for Parkinson's disease ${ }^{64}$, and up to $39 \%$ of patients started on a dopamine agonist will develop an ICD 65 .

An important question is whether impulsive ICD's result from loss of executive functions or from alterations in value-based decision-making. Patients with ICD given dopamine agonists performed worse on a delayed discounting task, which involves value-based decisionmaking, but normal on a tests of executive function, compared to Parkinson's patients without ICD's 66,67. In fact, patients with ICD in general perform better on tests of executive function compared with patients without ICD's ${ }^{68}$. Impaired delayed discounting appears to be due to undervaluing future rewards, rather than increasing the perceived value of immediate rewards ${ }^{69}$, and risky behavior in ICD patients is higher for potential gains rather than for loss aversion ${ }^{70}$.

Harv Rev Psychiatry. Author manuscript; available in PMC 2018 November 01. 
The patient in this case presented to his neurologist for evaluation. He had a tremor in his left hand at rest and with walking that improved with action. His facial expression was masked and he had a reduced blink rate. He had bradykinesia and rigidity in his left greater than right arm and leg, difficulty rising from a chair, and festinating gait. He performed normal on bedside cognitive testing, although he would often start a cognitive test before the instructions had been fully explained. On behavioral interview he expressed remorse and guilt about his behavior, but felt an inability to control himself. A dopamine transporter PET scan (Figure 2) showed reduced dopamine transporter uptake in the basal ganglia, consistent with a diagnosis of Parkinson's Disease.

On neuropsychological testing he demonstrated impaired delayed discounting, but performed normally on tests of executive functioning. After stopping his dopamine agonist medication, he no longer felt the urge to gamble, solicit prostitutes, or use drugs. His neuropsychological testing was repeated and he no longer showed evidence of impaired delayed discounting.

In pre-trial hearings, his neurologist testified that his history and exam findings were consistent with a diagnosis of Parkinson's disease. His dopamine transporter scan was not felt to significantly change the confidence of this diagnosis and was not presented at the hearing. His history of behavioral changes and impaired delayed discounting while on dopamine agonist, and resolution of this behavior and neuropsychological change on cessation of the medication, was argued to provide causal evidence for dopamine-induced ICD. After hearing the neurologist's testimony, his debtors agreed to drop all criminal charges on the condition that the patient pay back the money that was owed over time.

\section{Case 2: AD and financial capacity}

A 73-year-old man with mild dementia comes for clinical follow-up with his daughter. Previously, he had stopped working as a salesperson due to his dementia and stopped driving due to cataracts, but had no other impairment in his activities of daily living (ADL's). His daughter expresses concern about his ability to maintain his finances. He missed paying several bills in the last 3 months. Moreover, when out to dinner last week he had significant difficulty paying the bill. He recently invested in a dubious real-estate venture after talking with a telemarketer on the phone. When confronted, he denies that there are any problems with his ability to manage his finances.

In the above case, the patient presented to neurology clinic, where he was found to have significantly impaired short term memory. He could only perform one calculation correctly on serial 7's, and had difficulty copying a cube. At the end of the interview, he asked several questions again that had been answered near the beginning of the interview. On behavioral interview, he could not reason through common financial situations, although he lacked an awareness of this impairment. An FDG-PET scan (Figure 3) showed hypometabolism of the parietal and temporal lobes, consistent with a diagnosis of Alzheimer's Disease.

On more formal neuropsychological testing, he had mild executive function deficits, as well as specific deficits in arithmetic. He performed poorly on a financial capacity task, and demonstrated little awareness of his deficits. He was able to identify his daughter as his 
durable power of attorney and healthcare proxy, clearly describing what this entailed, as well as other options he had regarding this decision.

His physician determined that his history, exam findings, and neuroimaging changes were consistent with a diagnosis of Alzheimer's Disease. The patient had abnormalities on examination and neuropsychological testing that impaired his ability to make financial decisions, including poor memory, impaired calculations, and impaired reasoning. Moreover, he had deficits in meta-cognition that prevented him from recognizing his impairments. Finally, he was found to be impaired on a formal financial capacity task. His neurologist therefore determined that he lacked the capacity to make financial decisions.

Because of this, the patient would need a surrogate decision-maker to help with financial decisions. Despite the aforementioned impairments in decision-making, the patient was able to express understanding what a surrogate decision-maker would do, select his daughter (a reasonable choice as his closest family member who was actively involved in his care), and consistently maintain this decision over time. His neurologist therefore determined that he did have decision-making capacity to complete a healthcare proxy form and to name his daughter as his durable power of attorney.

\section{Conclusions}

Classically the law has assessed a subject's capacity for decision-making based on their ability to reason through potential consequences of and alternatives to choices. However, research has revealed that decision-making is a complex process that depends on multiple different executive functions, value-based predictions of reward and punishment, and metacognition (Table 1). Moreover, different types of choices will involve these processes to varying degrees. Classic neuropsychological tests of the variety of traditional cognitive domains, such as language, memory, and executive functions, may not closely align the processes necessary to make important types of decisions. Tasks probing other neuropsychological processes should therefore be incorporated into evaluations of persons with dementia where determinations of capacity are being considered.

Specific assessments of capacity can increase the ecological validity of behavioral evidence used to determine capacity. Examples include financial capacity assessments 41,42 and informed consent vignettes. ${ }^{31-34}$ However, such measures would benefit from including aspects of value-based decision-making and meta-cognition. Moreover, it is unclear the extent to which more ecologically valid measures of moral decision-making ${ }^{71}$ will be useful in arguing for diminished capacity in competency cases, as more research is needed to determine if such an association is valid.

Finally, neuroimaging is currently of little added value beyond behavioral data in determining capacity and competency. ${ }^{54}$ The exception to this is that neuroimaging can improve the diagnostic certainty of specific types of dementia, which can be useful in determining a causal etiology for behavioral changes. It is unclear if neuroimaging will have further utility in such matters in the future.

Harv Rev Psychiatry. Author manuscript; available in PMC 2018 November 01. 


\section{References}

1. Budson, AE., Solomon, PR. Memory Loss, Alzheimer's Disease, and Dementia A Practical Guide for Clinicians. Elsevier Health Sciences; 2015.

2. Gleichgerrcht E, Ibanez A, Roca M, Torralva T, Manes F. Decision-making cognition in neurodegenerative diseases. Nat Rev Neurol. 2010; 6:611-623. [PubMed: 21045795]

3. Hebert LE, Weuve J, Scherr PA, Evans DA. Alzheimer disease in the United States (2010-2050) estimated using the 2010 census. Neurology. 2013; 80:1778-1783. [PubMed: 23390181]

4. Ruff CC, Fehr E. The neurobiology of rewards and values in social decision making. Nat Rev Neurosci. 2014; 15:549-562. [PubMed: 24986556]

5. Rosen HJ, et al. Metacognition in the behavioral variant of frontotemporal dementia and Alzheimer's disease. Neuropsychology. 2014; 28:436-47. [PubMed: 24548124]

6. Wilson RS, Sytsma J, Barnes LL, Boyle PA. Anosognosia in Dementia. Curr Neurol Neurosci Rep. 2016; 16:77. [PubMed: 27438597]

7. Miller EK, Cohen JD. A <scp $>\mathrm{N}</$ scp $>$ I $<$ scp $>$ NTEGRATIVE $</$ scp $>$ T $<$ scp $>$ HEORY OF $</$ scp $>$ P $<$ scp $>$ REFRONTAL $</$ scp $>$ C $<$ scp $>$ ORTEX $</$ scp $>$ F $<$ scp $>$ UNCTION $</$ scp $>$. Annu Rev Neurosci. 2001; 24:167-202. [PubMed: 11283309]

8. Stuss DT, Alexander MP. Is there a dysexecutive syndrome? Philos Trans R Soc Lond B Biol Sci. 2007; 362:901-15. [PubMed: 17412679]

9. Gazzaley, A., D’Esposito, M. Unifying prefrontal cortex function: Executive control, neural networks, and top-down modulation; Hum Front lobes Funct Disord. 22007. p. 187-206.<http:// search.ebscohost.com/login.aspx? direct=true \&db=psyh\&AN=2006-23347-013\&lang=fr\&site=ehost-live>

10. Daffner, KR., Willment, KC. Dementia. Oxford University Press; 2014. p. 71-107.

11. Norman, DA., Shallice, T. Consciousness and Self-Regulation. Springer; US: 1986. p. 1-18.

12. Baddeley A. Working memory: theories, models, and controversies. Annu Rev Psychol. 2012; 63:1-29. [PubMed: 21961947]

13. Grafman, J. Principles of Frontal Lobe Function. Oxford University Press; 2002. p. 292-310.

14. Mesulam, M-M. Principles of Frontal Lobe Function. Oxford University Press; 2002. p. 8-30.

15. Posner MI. Orienting of attention. Q J Exp Psychol. 1980; 32:3-25. [PubMed: 7367577]

16. Corbetta M, Shulman GL. Control of goal-directed and stimulus-driven attention in the brain. Nat Rev Neurosci. 2002; 3:201-15. [PubMed: 11994752]

17. Seeley WW, et al. Dissociable Intrinsic Connectivity Networks for Salience Processing and Executive Control. J Neurosci. 2007; 27:2349-2356. [PubMed: 17329432]

18. Fox MD, Corbetta M, Snyder AZ, Vincent JL, Raichle ME. Spontaneous neuronal activity distinguishes human dorsal and ventral attention systems. Proc Natl Acad Sci U S A. 2006; 103:10046-51. [PubMed: 16788060]

19. Damasio AR. The Somatic Marker Hypothesis and Possible functions of the prefrontal cortex. Philos Trans R Soc Lond B Biol Sci. 1996; 351:1413-20. [PubMed: 8941953]

20. Bechara A, Damasio H, Damasio AR. Emotion, decision making and the orbitofrontal cortex. Cereb Cortex. 2000; 10:295-307. [PubMed: 10731224]

21. Dolan RJ, Dayan P. Goals and Habits in the Brain. Neuron. 2013; 80:312-325. [PubMed: 24139036]

22. Damasio AR. The somatic marker hypothesis and the possible functions of the prefrontal cortex. Philos Trans R Soc Lond B Biol Sci. 1996; 351:1413-20. [PubMed: 8941953]

23. Bechara A, Damasio H, Tranel D, Damasio AR. Deciding Advantageously Before Knowing the Advantageous Strategy. Science (80- ). 1997; 275:1293-1295.

24. Shany-Ur T, et al. Self-awareness in neurodegenerative disease relies on neural structures mediating reward-driven attention. Brain. 2014; 137:2368-81. [PubMed: 24951639]

25 . Cosentino $\mathrm{S}$, et al. The right insula contributes to memory awareness in cognitively diverse older adults. Neuropsychologia. 2015; 75:163-169. [PubMed: 26049091]

26. Perrotin A, et al. Anosognosia in Alzheimer disease: Disconnection between memory and selfrelated brain networks. Ann Neurol. 2015; 78:477-486. [PubMed: 26085009] 
27. Moye J, Marson DC, Edelstein B. Assessment of capacity in an aging society. Am Psychol. 2013; 68:158-171. [PubMed: 23586491]

28. Moye J, Naik AD. Preserving Rights for Individuals Facing Guardianship. JAMA. 2011; 305:936. [PubMed: 21364144]

29. Appelbaum PS, Grisso T. Assessing Patients' Capacities to Consent to Treatment. N Engl J Med. 1988; 319:1635-1638. [PubMed: 3200278]

30. Etchells E, et al. Assessment of patient capacity to consent to treatment. J Gen Intern Med. 1999; 14:27-34. [PubMed: 9893088]

31. Marson DC, Ingram KK, Cody HA, Harrell LE. Assessing the competency of patients with Alzheimer's disease under different legal standards. A prototype instrument. Arch Neurol. 1995; 52:949-54. [PubMed: 7575221]

32. Appelbaum PS, Grisso T. The MacArthur Treatment Competence Study. I: Mental illness and competence to consent to treatment. Law Hum Behav. 1995; 19:105-26. [PubMed: 11660290]

33. Grisso T, Appelbaum PS, Mulvey EP, Fletcher K. The MacArthur Treatment Competence Study. II: Measures of abilities related to competence to consent to treatment. Law Hum Behav. 1995; 19:127-48. [PubMed: 11660291]

34. Grisso T, Appelbaum PS. The MacArthur Treatment Competence Study. III: Abilities of patients to consent to psychiatric and medical treatments. Law Hum Behav. 1995; 19:149-74. [PubMed: 11660292]

35. Marson DC, Cody HA, Ingram KK, Harrell LE. Neuropsychologic predictors of competency in Alzheimer's disease using a rational reasons legal standard. Arch Neurol. 1995; 52:955-9. [PubMed: 7575222]

36. Marson DC, Chatterjee A, Ingram KK, Harrell LE. Cognitive Predictors of capacity to consent in Alzheimer's disease using three different legal standards. Neurology. 1996; 46:666-672. [PubMed: 8618664]

37. Sessums LL, Zembrzuska H, Jackson JL. Does this patient have medical decision-making capacity? JAMA. 2011; 306:420-7. [PubMed: 21791691]

38. Gambina G, et al. Awareness of cognitive deficits and clinical competence in mild to moderate Alzheimer's disease: their relevance in clinical practice. Neurol Sci. 2014; 35:385-90. [PubMed: 23959532]

39. Huthwaite JS, et al. Declining medical decision-making capacity in mild AD: a two-year longitudinal study. Behav Sci Law. 2006; 24:453-63. [PubMed: 16883623]

40. Okonkwo OC, et al. Medical decision-making capacity in mild cognitive impairment: a 3-year longitudinal study. Neurology. 2008; 71:1474-80. [PubMed: 18981368]

41. Marson DC. Clinical and ethical aspects of financial capacity in dementia: A commentary. Am J Geriatr Psychiatry. 2013; 21:382-390. [PubMed: 23498385]

42. Marson DC, et al. Assessing financial capacity in patients with Alzheimer disease: A conceptual model and prototype instrument. Arch Neurol. 2000; 57:877-84. [PubMed: 10867786]

43. Sherod MG, et al. Neurocognitive predictors of financial capacity across the dementia spectrum: Normal aging, mild cognitive impairment, and Alzheimer's disease. J Int Neuropsychol Soc. 2009; 15:258-67. [PubMed: 19203439]

44. Griffith HR, et al. Magnetic resonance imaging volume of the angular gyri predicts financial skill deficits in people with amnestic mild cognitive impairment. J Am Geriatr Soc. 2010; 58:265-74. [PubMed: 20374402]

45. Bickart KC, et al. Atrophy in distinct corticolimbic networks in frontotemporal dementia relates to social impairments measured using the Social Impairment Rating Scale. J Neurol Neurosurg Psychiatry. 2014; 85:438-48. [PubMed: 24133285]

46. Widera E, Steenpass V, Marson D, Sudore R. Finances in the older patient with cognitive impairment: 'He didn't want me to take over'. JAMA. 2011; 305:698-706. [PubMed: 21325186]

47. Karlawish JH, et al. Addressing the ethical, legal, and social issues raised by voting by persons with dementia. JAMA. 2004; 292:1345-50. [PubMed: 15367557]

48. Appelbaum PS, Bonnie RJ, Karlawish JH. The capacity to vote of persons with Alzheimer's disease. Am J Psychiatry. 2005; 162:2094-100. [PubMed: 16263849]

Harv Rev Psychiatry. Author manuscript; available in PMC 2018 November 01. 
49. Greene E, Bornstein BH, Dietrich H. Granny, (don't) get your gun: competency issues in gun ownership by older adults. Behav Sci Law. 2007; 25:405-23. [PubMed: 17559168]

50. Mertens B, Sorenson SB. Current considerations about the elderly and firearms. Am J Public Health. 2012; 102:396-400. [PubMed: 22390501]

51. Bernat, JL. Ethical issues in neurology. Lippincott Williams \& Wilkins; 2008.

52. Faigman DL, Monahan J, Slobogin C. Group to Individual (G2i) Inference in Scientific Expert Testimony. Univ Chicago Law Rev. 2014; 81:417-480.

53. Fisher CE, Faigman DL, Appelbaum PS. Toward a Jurisprudence of Psychiatric Evidence: Examining the Challenges of Reasoning from Group Data in Psychiatry to Individual Decisions in the Law. Univ Miami Law Rev. 2014; 1:685-754.

54. Morse S. Criminal Law and Common Sense: An Essay on the Perils and Promise of Neuroscience. Marquette Law Rev. 2015; 99:39-74.

55. Wasserman D, Johnston J. Seeing responsibility: can neuroimaging teach us anything about moral and legal responsibility? Hastings Cent Rep. 2014; (Spec No):S37-49. [PubMed: 24634084]

56. Meltzer CC, et al. Guidelines for the ethical use of neuroimages in medical testimony: Report of a multidisciplinary consensus conference. Am J Neuroradiol. 2014; 35:632-637. [PubMed: 23988754]

57. McKhann GM, et al. The diagnosis of dementia due to Alzheimer's disease: recommendations from the National Institute on Aging-Alzheimer's Association workgroups on diagnostic guidelines for Alzheimer's disease. Alzheimers Dement. 2011; 7:263-9. [PubMed: 21514250]

58. Rascovsky K, et al. Sensitivity of revised diagnostic criteria for the behavioural variant of frontotemporal dementia. Brain. 2011; 134:2456-77. [PubMed: 21810890]

59. James BD, Boyle PA, Yu L, Han SD, Bennett DA. Cognitive Decline Is Associated with Risk Aversion and Temporal Discounting in Older Adults without Dementia. PLoS One. 2015; 10:e0121900. [PubMed: 25838074]

60. Han SD, Boyle PA, James BD, Yu L, Bennett DA. Mild Cognitive Impairment and Susceptibility to Scams in Old Age. J Alzheimer's Dis. 2015; 49:845-851.

61. Weintraub D, David AS, Evans AH, Grant JE, Stacy M. Clinical spectrum of impulse control disorders in Parkinson's disease. Mov Disord. 2015; 30:121-127. [PubMed: 25370355]

62. Antonini A, et al. Impulsivity and compulsivity in drug-naïve patients with Parkinson's disease. Mov Disord. 2011; 26:464-8. [PubMed: 21312278]

63. Hassan A, et al. Dopamine agonist-triggered pathological behaviors: Surveillance in the PD clinic reveals high frequencies. Parkinsonism Relat Disord. 2011; 17:260-264. [PubMed: 21310646]

64. Weintraub D, et al. Impulse control disorders in Parkinson disease: a cross-sectional study of 3090 patients. Arch Neurol. 2010; 67:589-95. [PubMed: 20457959]

65. Bastiaens J, Dorfman BJ, Christos PJ, Nirenberg MJ. Prospective cohort study of impulse control disorders in Parkinson's disease. Mov Disord. 2013; 28:327-33. [PubMed: 23283708]

66. Antonelli F, et al. Dopamine-agonists and impulsivity in Parkinson's disease: impulsive choices vs. impulsive actions. Hum Brain Mapp. 2014; 35:2499-506. [PubMed: 24038587]

67. Leroi I, et al. Dopaminergic influences on executive function and impulsive behaviour in impulse control disorders in Parkinson's disease. J Neuropsychol. 2013; 7:306-25. [PubMed: 23901888]

68. Siri C, et al. Long-term cognitive follow-up of Parkinson's disease patients with impulse control disorders. Mov Disord. 2015; 30:696-704. [PubMed: 25757654]

69. Housden CR, O’Sullivan SS, Joyce EM, Lees AJ, Roiser JP. Intact reward learning but elevated delay discounting in Parkinson's disease patients with impulsive-compulsive spectrum behaviors. Neuropsychopharmacology. 2010; 35:2155-64. [PubMed: 20631686]

70. Voon V, et al. Dopamine agonists and risk: impulse control disorders in Parkinson's disease. Brain. 2011; 134:1438-46. [PubMed: 21596771]

71. Greene JD, Sommerville RB, Nystrom LE, Darley JM, Cohen JD. An fMRI investigation of emotional engagement in moral judgment. Science. 2001; 293:2105-8. [PubMed: 11557895]

Harv Rev Psychiatry. Author manuscript; available in PMC 2018 November 01. 
A.
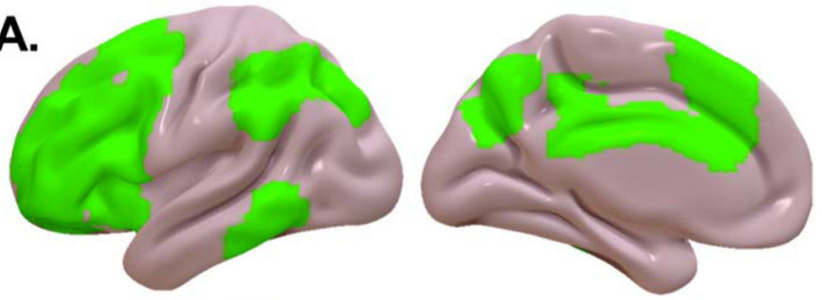

B.
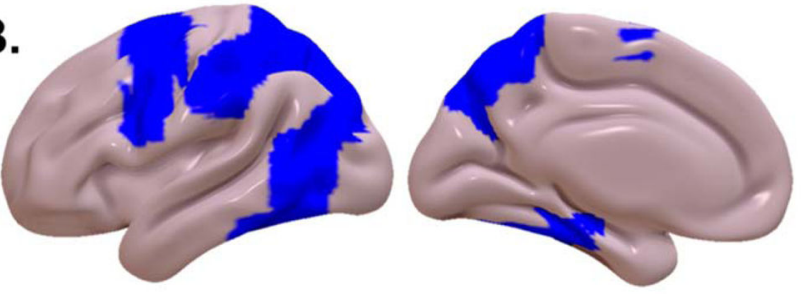

C.
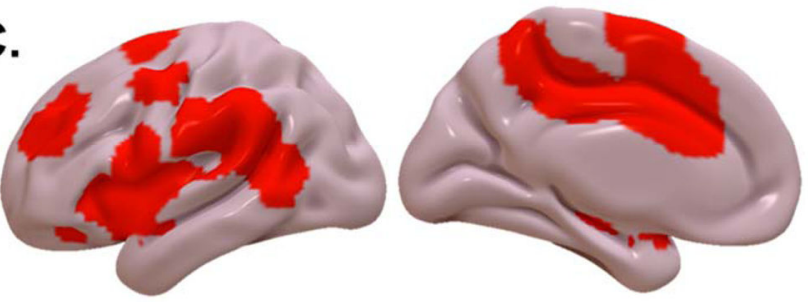

D.

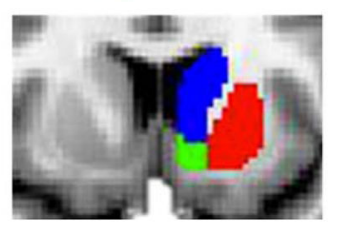

Figure 1. Brain Regions Involved in Decision Making

The frontoparietal network (A), dorsal attention network (B), and ventral attention network (C) are involved in executive functions. (D) the nucleus accumbens (green), dorsal striatum (blue), and ventral striatum (red) are involved in motivation, reward, and punishment. 

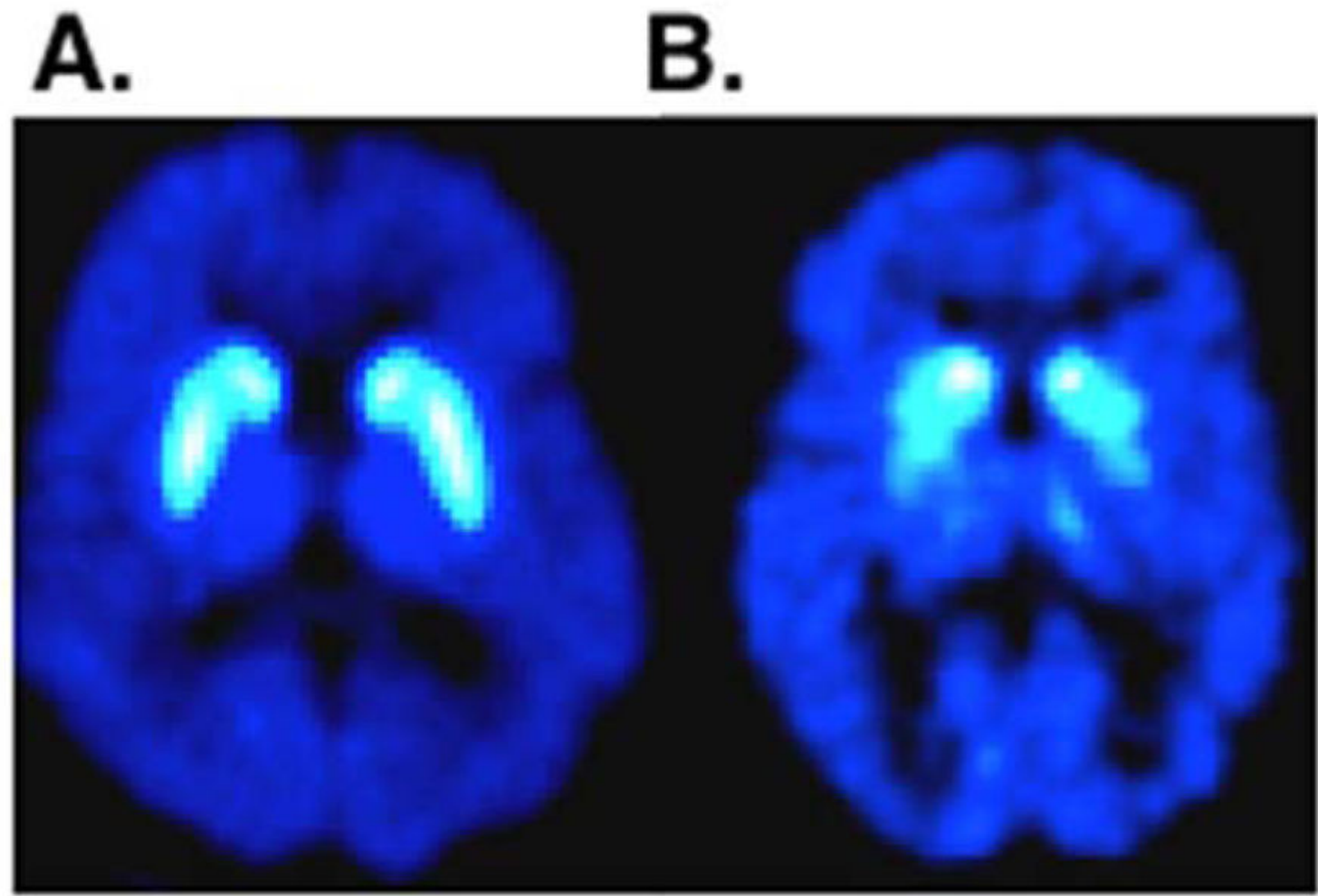

Figure 2. Representative PET scan from patient with Parkinson's Disease

Dopamine tracer (DAT) scan showing normal update of tracer in the basal ganglia in a patient with Alzheimer's Disease (A) vs. reduced uptake in a representative patient with Parkinson's Disease (B). 


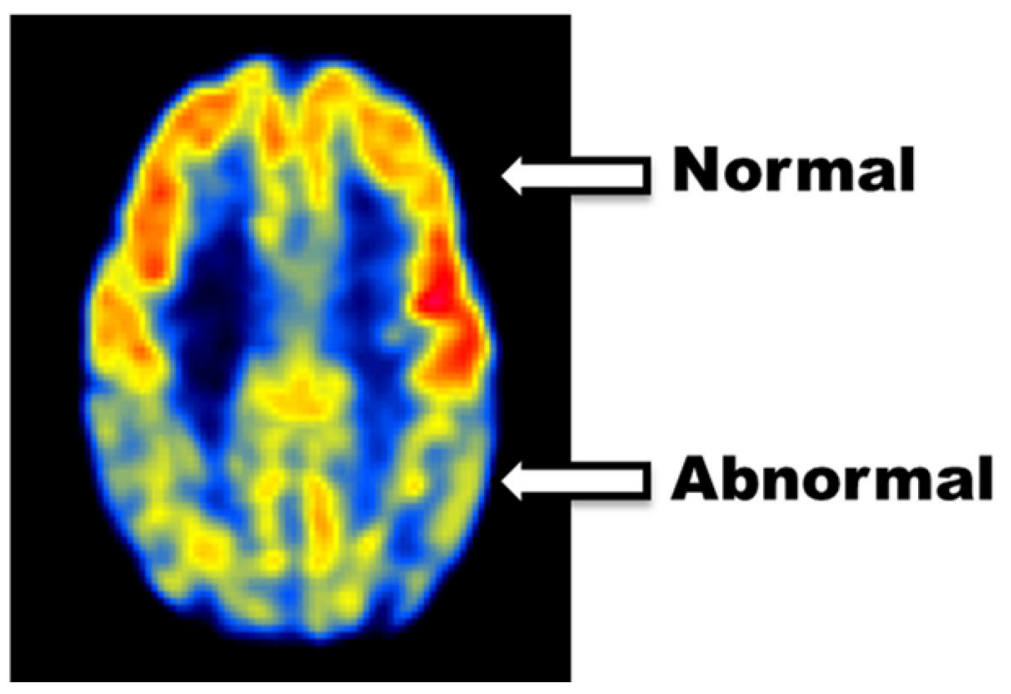

Figure 3. FDG-PET scan of a representative patient with Alzheimer's Disease

Red and yellow areas in the front of the brain represent normal metabolic activity. Areas in blue and green posteriorly represent reduced metabolic activity. 


\section{Table 1}

Example Tasks for Psychological processes contributing to decision-making

\begin{tabular}{|ll|}
\hline Psychological Process & Task \\
\hline Value-based decision-making & Delayed Discounting \\
& Risk Aversion \\
& Iowa Gambling Task \\
Meta-Cognition & Ease of Knowing \\
& Feeling of Knowing \\
& Judgement of Knowing \\
& Performance Confidence Ratings \\
& Feeling of Knowing \\
& Judgement of Knowing \\
& Performance Confidence Ratings \\
\hline
\end{tabular}

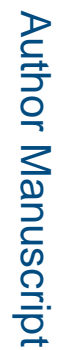

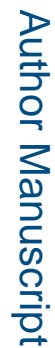

Harv Rev Psychiatry. Author manuscript; available in PMC 2018 November 01. 